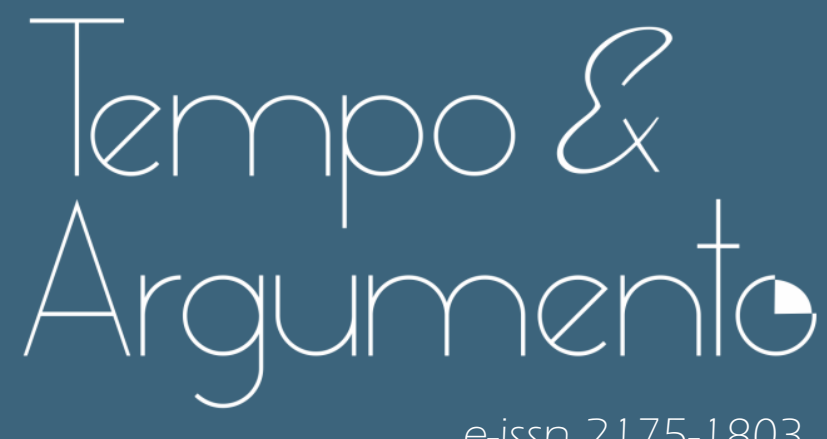

e-issn 2175-1803

\title{
Conflito, discriminação e segregação na Palestina ocupada: etnocracia como síntese teórica possível
}

- Fábio Bacila Sahd

Doutor em Humanidades, Direitos e outras Legitimidades pela Universidade de São Paulo (USP). Professor da Universidade Federal do Maranhão (UFMA).

Bacabal, MA - BRASIL

lattes.cnpq.br/3892346066752212

fabiobacila@hotmail.com

(D) orcid.org/0000-0003-3802-5505

Para citar este artigo:

SAHD, Fábio Bacila. Conflito, discriminação e segregação na Palestina ocupada: etnocracia como síntese teórica possível. Tempo e Argumento,

Florianópolis, v. 13, n. 32, e0 107, jan./abr. 2021.

doi http://dx.doi.org/10.5965/2175180313322021e0107 


\title{
Conflito, discriminação e segregação na Palestina ocupada: etnocracia como síntese teórica possível ${ }^{1}$
}

\begin{abstract}
Resumo
O presente artigo opera uma revisão bibliográfica crítica acerca da discriminação e práticas de segregação na Palestina ocupada. São expostas as considerações de diferentes autores, divididas conforme entendem a ocupação, mas sobretudo a partir das forças históricas que constituem o Estado de Israel como etnocracia, quais sejam: o nacionalismo, o colonialismo e o capitalismo. Portanto, etnocracia é o conceito que faz convergir as diferentes interpretações aqui apresentadas, enfatizando-se suas aproximações. Ademais, a bibliografia é comparada a relatórios de direitos humanos da ONU e de ONGs, demonstrando sua complementaridade.
\end{abstract}

Palavras-chave: Sionismo. Ocupação israelense. Territórios Palestinos Ocupados. Colonialismo.

\section{Conflict, discrimination and segregation in occupied Palestine: ethnocracy as a possible theoretical synthesis}

\begin{abstract}
This article performs a critical bibliographic review on discrimination and segregation practices in occupied Palestine. The considerations of different authors are exposed, divided as they understand the occupation, but above all from the historical forces that constitute the State of Israel as an ethnocracy, namely: nationalism, colonialism and capitalism. Therefore, ethnocracy is the concept that converges the different interpretations presented here, emphasizing their approximation. Furthermore, the bibliography is compared to UN and NGO human rights reports, demonstrating its complementarity.
\end{abstract}

Keywords: Zionism. Israeli Occupation. Occupied Palestinian Territories. Colonialism.

O ano é 2014. Richard Falk entrega seu último balanço à frente da relatoria especial apontada pelo Conselho de Direitos Humanos da ONU (CDH-ONU) para apurar as violações praticadas por Israel nos Territórios Palestinos Ocupados (TPO). O jurista, então, reiterou pedidos feitos em relatórios anteriores (2007 e 2011) para que a Corte Internacional de Justiça se posicionasse acerca do tema, mais especificamente, se "elementos da ocupação [israelense] constituem formas de colonialismo e apartheid", além de "limpeza étnica". Como a Corte não

\footnotetext{
Pesquisa financiada pelo CNPQ.
} 
havia emitido nenhum parecer até então, o próprio Falk analisou suscintamente a fundamentação dessas alegações, observando políticas e práticas israelenses "sob a lente da proibição internacional de discriminação, segregação e apartheid". Suas constatações são assertivas, mas não surpreendentes, se consideradas à luz da bibliografia crítica e da vasta documentação produzida pela própria ONU e por ONGs, desde o final dos anos 1960. Para definir a situação nos TPO, Falk recorreu à palavra hebraica hafrada, utilizando-a como sinônimo do termo africâner apartheid e relacionando-a aos "evidentes objetivos anexionistas, colonialistas e de limpeza étnica de Israel" (UNITED NATIONS, 2014, p. 4).

Tal relatório não foi nem pioneiro nem derradeiro, com comparações semelhantes figurando na bibliografia e em diversos documentos. Desse modo, as analogias e o enquadramento jurídico na legislação internacional feitos por Falk podem surpreender o leitor incauto ou leigo, mas não sobressaltam quem está mais familiarizado com a colonização da Palestina e o conflito decorrente (ABUNIMAH, 2006; BISHARA, 2003; COCONI, 2010; OSMAN; DADDO, 2013; PAPPÉ, 2015; SAID, 1992; 1998; 2006; UNITED NATIONS, 1971; 2007; 2008; 2017; YIFTACHEL, 2006; ZUREIK, 2016).

A proposta do presente artigo é um balanço sintético acerca do tema que visa tanto introduzir as linhas interpretativas mais básicas quanto apontar portos seguros para quem ousa navegar pelos mares conturbados desse já centenário conflito na "Terra Santa". Desde o final do século XIX, o sionismo, como movimento colonial/nacional judaico e uma das alternativas ao antissemitismo, agrupou pessoas, religiosas e laicas, de diferentes países, especialmente europeus. Se a opção pela Palestina (em detrimento de Uganda e Patagônia) encerrou as discussões sobre o local no qual seria erigido o "Estado judeu", deu início aos debates sobre a "questão oculta". No caso, o que fazer com a população nativa, politicamente identificada com outros nacionalismos, que não o sionismo. Descrita nesses termos em artigo de Yitzhak Epstein (1907), respostas à "questão oculta" já foram esboçadas antes, como pelo próprio "pai fundador" do Movimento Sionista Internacional (MSI), Theodore Herzl, que sugeriu uma "transferência" gradativa e sigilosa desse contingente populacional indesejado (MASALHA, 2008; PAPPE, 2008). 
Com o início das ondas imigratórias para a Palestina organizadas pelo MSI, as tensões interétnicas foram se acentuando. A situação se agravou ainda mais com o reconhecimento dos objetivos coloniais/nacionais sionistas pela GrãBretanha (por meio da Declaração Balfour, feita por seu chanceler, em 1917), que se tornou a potência mandatária do território após a Primeira Guerra e inseriu a "criação do lar nacional judaico" na Constituição de seu mandato sobre a Palestina. Assim, britânicos e sionistas reproduziram a situação típica dos colonialismos: a inferiorização e discriminação dos autóctones por uma perspectiva orientalista/eurocêntrica de tutela necessária, desconsiderando totalmente sua vontade e anseio de autodeterminação. A legitimação "internacional" desse conserto se deu por meio da Liga das Nações, mais especificamente, pelo artigo vinte e dois do Tratado de Versalhes, segundo o qual, para seu próprio bem estar, caberia a uma potência europeia tutelar nativos que ainda não estivessem preparados para exercer sua soberania de forma independente (FIELDHOUSE, 2006; SAHD, 2010).

Apesar de todas as mudanças conjunturais, a "questão oculta" persiste, dos primórdios do MSI até os dias de hoje, perpassando o Mandato Britânico e seu término, a fundação do Estado de Israel, em 1948², e a ocupação e colonização do restante do território da Palestina histórica, a partir de 1967. Há mais de um século, a "questão dos nativos" vem sendo solucionada por um processo de sistemática divisão, discriminação, segregação e expulsão de uma parte considerável da população, em prol de outra, cuja maioria é constituída de emigrantes recentes ou de seus descendentes diretos. Eis mais um capítulo do

\footnotetext{
2 Por meio da resolução 181 de sua Assembleia Geral, aprovada em 1947, a ONU recomendou a partilha do território palestino em dois Estados étnicos, um palestino e outro judaico, o que foi prontamente rejeitado pelos Estados árabes. Em 15 de maio de 1948, o movimento sionista proclamou o Estado de Israel, deflagrando-se um conflito interno contra sua população palestina e outro externo, contra os países vizinhos. Em decorrência, as composições demográfica e das propriedades fundiárias do recém-fundado Estado israelense foram drasticamente modificadas a partir de um processo de limpeza étnica, que consolidou seu caráter majoritariamente judaico a partir da expulsão e desapropriação de centenas de milhares de palestinos, sendo essa a origem do duradouro problema dos refugiados de 1948, que conforme a Resolução 194 da ONU, aprovada em 1949, devem ser reintegrados ou indenizados, o que segue sem implementação, assim como a criação do Estado palestino. Em 1967, Israel ocupa e passa a colonizar o restante do território do antigo Mandato Britânico sobre a Palestina, complexificando ainda mais a situação ao apagar, na prática, as fronteiras iniciais e reconfigurar a disposição populacional. Diferentemente das expectativas geradas, os acordos de Oslo, firmados em meados dos anos 1990, não culminaram no acordo final previsto, inviabilizado pela falta de consenso e continuidade da colonização e violência intercomunitária.
} 
colonialismo, como bem apontado por tantos autores, na esteira de Edward Said, e reconhecido por Falk, mais recentemente. É verdade que se trata de um episódio bastante peculiar, e possivelmente terminal, mas para nós, brasileiras e brasileiros, minimamente conhecedores da discriminação, desapropriação e opressão sistemática imposta aos povos indígenas por nosso Estado e sociedade, não é complexo compreender outras situações coloniais, sendo salutares as comparações.

Consta em dezenas de resoluções da ONU que, as práticas israelenses colocam em xeque "a paz e a segurança internacionais" e toda a arquitetura jurídica e protetiva internacional, que deveria resguardar a dignidade humana e os direitos individuais e coletivos. Seus preceitos mais básicos são negados, como o direito à autodeterminação e a interdição da discriminação, segregação, colonização e aquisição de territórios pela força (FALK, 2009). Há uma robusta bibliografia, que busca explicar esse ininterrupto e, podemos dizer, extemporâneo processo colonial que, como tal, viola os direitos humanos e humanitários de forma estrutural. A seguir, apresentaremos algumas linhas interpretativas, antes complementares que mutuamente excludentes, que auxiliam em sua compreensão, priorizando as convergências - para uma análise mais detida das divergências, vide a obra recente de Elia Zureik (2016). Vale destacar que, tal situação vem sendo legitimada por governos que integram a recente ascensão dos neofascismos ou neopopulismos, a exemplo do "Plano Trump", atualização da Declaração Balfour, que decide pelos palestinos sem eles. O conceito de etnocracia, apresentado ao final, serve de instrumento analítico sintético, que permite incorporar diferentes visões e articulá-las em torno do que seria uma configuração específica de Estado que, necessariamente, atrita com a legislação internacional, criando expedientes ou subterfúgios para continuar suas práticas, o que guarda vínculos com o neofascismo global (tema este que pretendemos abordar em trabalho futuro).

\section{A questão do nacionalismo}

Uma primeira chave teórica que nos ajuda a compreender a discriminação e segregação na Palestina histórica é o nacionalismo, mais especificamente, sua 
vertente judaica. De modo geral, os nacionalismos são movimentos que reivindicam o controle, a soberania de determinada "nação" sobre um território, onde deve ser constituído seu "Estado nacional". Em territórios onde habitam mais de um grupo étnico, os nacionalismos geram conflitos sobre a definição de quem tem ou não direito à condição de cidadão, sobre quem é o "legítimo" proprietário e quem pode ali viver como "hóspede" ou, no pior caso, deve ser expulso. As identidades nacionais se imbricam com as identidades étnicas, não raro, provocando conflitos e deslocamentos populacionais. Desse modo, em si, a instituição "Estado nacional" tem um potencial excludente, poder-se-ia dizer, até genocida, tendo propensão a provocar "engenharias sociais", pois os limites de pertencimento étnico-nacional, frequentemente, são estreitos, excluindo a alteridade em oposição a qual o próprio grupo dominante se define.

Na Palestina/Israel ${ }^{3}$, com o sionismo, não é diferente, à medida que, em sua quase totalidade, mantém reivindicações exclusivistas e opera um projeto de judaização do território disputado com os palestinos. Contudo, cabe destacar que, como movimento nacional é plural, tendo vertentes laicas e religiosas, e apresenta em seu histórico visões mais inclusivas, como aquelas defendidas no começo do século XX por Martin Bubber, mas que se tornaram muito minoritárias, quase insignificantes, ao longo do processo histórico de colonização (GORNY, 1987; PINSKY, 1978). Portanto, predominaram as visões restritivas e excludentes de quem tem “direito histórico" à soberania na Palestina, território mitificado e reivindicado na narrativa nacional/colonial do "povo judeu", tal qual inventada pelo sionismo por meio de uma revisão histórica negacionista, que ao negar a presença do outro se autolegitima (ALAM, 2009; SAND, 2008). Essa lógica não é contraditória, mas alinhada com os demais nacionalismos como "comunidades imaginadas" (ANDERSON, 2008), que no caso específico ressignificou o antissemitismo e a judeidade, revestindo-os do ideário nacionalista e do intrépido pioneiro colonizador (RABKIN, 2009; ZERTAL; ELDAR, 2007), assim como do martírio e da necessária reparação pelo Holocausto

\footnotetext{
Usamos essa expressão para nos referirmos à configuração atual do território, e de modo a contemplar a dupla reivindicação a ele, espelhando também nosso entendimento de que a saída deve se dar por uma solução não nacionalista/exclusivista, que pode passar pela criação de um Estado multinacional, cumprindo-se as etapas necessárias e fazendo os devidos reconhecimentos e reparações históricas.
} 
(ZERTAL, 2010). Sobre a fusão de nacionalismo e colonialismo e na identidade sionista, há semelhanças inequívocas com o movimento africâner, o que se reflete, inclusive, na segregação do outro legitimada por um discurso excepcionalista (ALAM, 2009; CORNEVIN, 1982; SUZMAN, 1999).

Em suas origens, o sionismo se apresenta como movimento colonial, nacional e solução definitiva ao antissemitismo. É uma versão peculiar tanto do colonialismo quanto dos movimentos nacionais fundados na Europa, sendo promotor da identidade ou do "renascimento nacional" do "povo judeu" criado por ele, portanto, reivindicando sua representação coletiva autêntica. Mas, diferentemente dos demais nacionalismos surgidos em solo europeu, o espaço ou "lar nacional" de exercício de sua soberania é um território colonial. Como alternativa ao antissemitismo, competiu com outras visões, como o internacionalismo operário e o "assimilacionismo", este inspirado pelos princípios da emancipação iluminista, que pauta a integração e os direitos iguais de todos os cidadãos, independentemente de sua fé. Mas, as relações entre sionismo e antissemitismo não são simples e lineares, pois acabam por convergir em visões e interesses, como explícito no próprio panfleto fundacional, o "Estado Judeu", escrito por Herzl (1947), nos últimos anos do século XIX. Afinal, ambos defendem a unicidade dos judeus, entendendo-os como raça ou povo, portanto, agrupam cidadãos de origem judaica de diferentes países em uma mesma categoria identitária. Ou seja, o discurso sionista acaba por reforçar a representação antissemita do "povo judeu", cuja lealdade primeira seria devotada a seu grupo “étnico/religioso" e não ao país de origem. Ademais, se a criação de um Estado nacional é a reivindicação sionista, também foi uma forma vislumbrada por antissemitas de "se livrarem" de seus conterrâneos e concidadãos indesejados, por eles demonizados e estrangeirizados/desnacionalizados. Inclusive, essa confluência provocou tensões nas comunidades judaicas de diferentes países e levou a acordos pragmáticos, como aqueles firmados com o III Reich por representantes do sionismo (RABKIN, 2009).

Retomando a questão das clivagens internas, além da divisão entre laicos e religiosos e das subdivisões entre estes, o sionismo também é atravessado por outras, como entre sociais-democratas e liberais, "moderados" ou "radicais" - 
para pegar aqui de empréstimo as categorias debatidas por Bobbio (2011) -, ainda que o grau de "igualitarismo" que possa propor seja limitado por seu próprio caráter étnico-nacional, em oposição a visões internacionalistas. Portanto, as posições mais à esquerda exorbitam do sionismo, apresentando-se em relação incômoda ou como alternativa a ele, como perceptível na posição de grupos locais, que reivindicam o multiculturalismo ou binacionalismo (LAOR, 2012). As divergências também passam pela definição de quais devem ser as fronteiras definitivas do Estado, sendo a questão demográfica central para que muitos rejeitem a inclusão da Cisjordânia ou "Judea e Samaria". Assim que, o condicionante étnico que define o in-group judaico e o out-group palestino está associado a uma territorialidade em disputa, restringindo-se gradativamente as áreas ocupadas pela alteridade desde o início do processo de colonização, com a discriminação étnica culminando na segregação ou em um "apartheid gradativo".

A conquista da terra, das águas e do território e a questão demográfica estão no coração do conflito, caracterizado pela expansão do sionismo/Israel e pela resistência palestina a esse processo de ampliação/restrição espacial, estando as fronteiras em constantemente redefinição (MASALHA, 2000; WEIZMAN, 2007). A lógica inerente é “mais terra, mais território e menos árabes", resumida na doutrina da "redenção da terra" (GORNY, 1987) ou "judaização o território" (YIFTACHEL, 2006). Enquanto os setores mais “moderados” reivindicam a fronteira anterior à expansão resultante da Guerra dos Seis Dias (1967), a ala "radical" exige a totalidade da Palestina histórica, além das Colinas de Golã. Alas messiânicas demandam ainda a Grande Israel prometida por Deus, que engloba territórios de vários outros países (RABKIN, 2009; SHELEF, 2010).

Enquanto nessa definição final das fronteiras misturam-se demandas políticas e religiosas com visões estratégicas e securitárias, os palestinos da Cisjordânia e Gaza estão submetidos a um sistema de ocupação militar, que conforme o direito internacional deveria ser temporário, mas já dura mais de cinco décadas e está associado à colonização, ensejando segregação e controle. Enquanto a alternativa moderada fora a "opção jordaniana" (troca territorial pela paz) ou o reconhecimento de uma entidade nacional autônoma para os 
palestinos (com territórios reduzidos e densamente povoados), o plano histórico do sionismo "radical"4 é a expulsão total ou a criação de zonas de autonomia, espécie de reservas nativas, semelhantes à proposta do apartheid sul-africano, que Said (1998) combateu como sendo a alternativa colocada na mesa pelos Acordos de Oslo.

A "questão oculta", ou a gestão do outro como remanescente indesejável, decorre do conflito entre as reivindicações e o projeto etnonacional sionista e palestino e as instituições internacionais, que interditam a "solução final" mais drástica para o problema, tal qual vislumbrada desde os primórdios pelos próprios pais fundadores do sionismo, ansiosos pela realização da idealizada completude nacional ou, no mínimo, por constituírem uma "confortável maioria". A proposta de "transferência populacional" ou "limpeza étnica" está no DNA desse nacionalismo e continua a figurar no debate público, tendo sido a alternativa executada, em 1948, para criar o Estado judeu em um território que, apesar de todos os esforços envidados pelo MSI para colonizar e adquirir terras, ainda estava predominantemente habitado por não judeus, que detinham a imensa maioria da propriedade fundiária (MASALHA, 2000; 2008; PAPPE, 2008). Vale lembrar que Falk também destaca os anseios de limpeza étnica (UNITED NATIONS, 2014), como explicitado no desejo de Netanyahu de incluir no Plano Trump a transferência do "triângulo" (região habitada por cidadãos palestinoisraelenses) para a autodeterminação palestina, à revelia da consulta e dos desejos desses "árabes israelenses", diminuindo sua representatividade na totalidade da população, que beira os 20\%, e causa pânico entre os demógrafos e eugenistas, de modo geral (ZUREIK, 2016).

Fato é que, em suas origens, o sionismo, além de ser um movimento nacional é um movimento colonial, implicando a necessidade de deslocamento populacional em massa, tanto do grupo étnico representado (“judaico”) para o território desejado quanto da população originária não assimilável para fora dele. Eis a origem das persistentes propostas de transferência populacional e do

\footnotetext{
Falar em "moderados" e "radicais", ao invés de "trabalhistas" e "revisionistas", corresponde ao fato de que, dentro da bibliografia especializada há quem aponte para a ampla disseminação e aceitação das visões territoriais e étnicas exclusivistas dentro dos sionismos, perpassando os diferentes espectros político-ideológicos, não obstante ser possível, em alguma medida, sobrepor as categorias.
} 
problema angular dos "refugiados palestinos de 1948", como bem apontado por Pappe (2008), Masalha (2008), dentre tantos outros. O Estado judeu só se mantém como tal pela permanente negação de implementação da resolução 194 da Assembleia Geral da ONU, que desde o final dos anos 1940, demanda o retorno e restituição dos refugiados de 1948. Ou seja, direitos são negados, e com eles a legislação internacional, para manter o caráter étnico-nacional do Estado de Israel, sob a justificativa de que assegura assim a autodeterminação judaica, ignora os direitos similares, tal qual ocorrera na África do Sul.

Em suma, é fundamental compreender o nacionalismo em si como uma das chaves teóricas explicativas das políticas de discriminação e segregação nos territórios palestinos, até hoje, sendo tal fenômeno responsável por apartheid, limpezas étnicas e genocídios também em outras localidades. É uma força histórica contraditória da modernidade, que expressa seu poder criativo e de amor na destruição do outro, ou a criação e manutenção de uma civilização ("Eros") se dá a partir da destruição e sobre os escombros de outra ("Tanatos") (ENRIQUEZ, 2001). Exemplo é a “Lei de Retorno" criada por Israel já nos primórdios do Estado, beneficiando apenas judeus (que podem se tornar cidadãos israelenses, independentemente do país de origem), enquanto o retorno e restituição dos refugiados palestinos é negado. A mesma lógica perpassa a expansão dos colonos e programas de anexação na Cisjordânia, culminando no cerco de Gaza. Ou seja, a definição étnico-nacionalista de quem é cidadão e de quem ameaça o caráter judaico do Estado nacional de Israel é central na segregação. Assim, no interior dos sionismos, conflitam diferentes visões territoriais, que têm em seu cerne, justamente, a opção por mais terras e/ou menos palestinos.

\section{Colonialismo e sionismo}

Ao lado do nacionalismo, o colonialismo é outro conceito fundamental para a compreensão da discriminação e segregação na Palestina, já que o sionismo é, concomitantemente, movimento nacional e empreendimento colonial, que reproduz sua ideologia e ethos. Ao longo de toda reflexão produzida pelas lideranças e "pais fundadores" de Israel, esse legado, indissociável do 
racismo, fica explícito, sendo caso emblemático a passagem do "O Estado Judeu”, em que Herzl (1947, p. 68) defende a busca de apoio internacional para sua empresa, à medida que se constituiria em uma "fortaleza da civilização contra a barbárie". Afinal, filhos de seu tempo e espaço social, o eurocentrismo orientalista (SAID, 2007) não deixou de perpassar e sustentar as representações de si, do outro e do mundo feitas pelos sionistas e registradas em seus discursos, diários, programas e manifestos.

De Herzl a Netanyahu, incidindo em todos os espectros do sionismo (do "liberal" e "trabalhista" ao "revisionista" e religioso-messiânico), sequer foi feita uma autocrítica política, mesmo após a onda descolonizadora e anticolonial, que varreu a superfície do globo e produziu uma revisão nas ciências, a exemplo do que foi denominado como teoria pós-colonial, ou "Epistemologias do sul" (SANTOS; MENESES, 2010). Ainda hoje, em propostas como o "Plano de Trump", permanecem seus pressupostos mais básicos, como a invisibilização e negação do outro e de seu direito à terra, descritos como espaços e corpos vazios, passíveis de serem conquistados, explorados, trabalhados e produzidos. A terra e a anima nullius permanecem a máxima, em se tratando da Palestina ocupada (SAID, 1992; MASALHA, 2000; QUIJANO, 2010). Assim, um hipotético acordo de paz foi proclamado em 2020, mesmo na ausência de qualquer palestino, afinal, não são sujeitos de direito, mas a versão coeva dos selvagens, dos bárbaros, na eterna guerra da civilização contra a barbárie, que inclusive continua a ser a metáfora utilizada para justificar o cerco e os massacres genocidas contra Gaza (SAHD, 2017; GRESH, 2020).

Esse substrato cultural também fica evidente nas expressões e práticas que circulam pela Palestina, do final do século XIX aos dias de hoje, como em outras realidades coloniais, destacando-se a lógica de "uma terra sem povo para um povo sem terra" ou "fazer o deserto florescer" (SAID, 1992). A invisibilização e negação do outro permanece como estratégia principal de (des)apropriação e expulsão populacional, judaizando o território assim "liberado". O acesso e uso da água, terras e lotes é inviabilizado, demarcando-se "zonas militares" ou mesmo "sítios de preservação ambiental ou histórica", onde nada pode ser construído ou reformado. Então, o território é considerado desocupado, portanto, 
passível de apropriação produtiva pelos colonos, portadores da civilização e do desenvolvimento econômico (AMNESTY INTERNATIONAL, 2006; 2007; BIMKOM, 2012; BIMKOM; B'TSELEM, 2009; CIVIC COALITION FOR DEFENDING PALESTINIANS RIGHTS IN JERUSALEM, 2009; HUMAN RIGHTS WATCH, 2010; WEIZMAN, 2007).

Nessa lógica, Gaza seria o último estágio da ocupação israelense, cuja lógica de concentração populacional ("máximo de palestinos em um mínimo de terras") é o modelo a ser reproduzido em toda a Cisjordânia (LI, 2006), como foi em outras experiências coloniais, a exemplo dos bantustões sul-africanos e de reservas indígenas diminutas na América Latina.

A própria ocupação e colonização da Cisjordânia é a continuidade da “judaização do território", iniciada no final do século XIX, "limpando-o" de sua população palestina (YIFTACHEL, 2006; ZERTAL, ELDAR, 2007). Do mesmo modo como ocorrido nas fronteiras israelenses anteriores à Guerra de 1967, os espaços em disputa são (des)apropriados, territorializados, renomeados, tentando-se apagar os vínculos físicos e simbólicos anteriores, como feito após a Nakba (1948), com centenas de vilas palestinas extintas, apagadas de mapas e de placas de sinalização de trânsito, sendo sua rememoração punida em Israel (BOUSSOIS, 2008; D’AMOURS, 2010; 2011).

Além dos motivos políticos, nacionais, ideológicos e econômicos, a colonização dos TPO também precisa ser compreendida a partir de sua justificativa central: a "questão da segurança israelense". Desde os primórdios, buscou-se o estabelecimento de linhas de defesa seguras ou um conceito de "segurança em profundidade", feita pelo constante monitoramento do território e dos fluxos populacionais pelas próprias colônias, como postos avançados. Desse modo, planos militares justificaram a ocupação e colonização de áreas específicas (enfatizando-se as zonas elevadas, como colinas e montanhas) por motivos securitários (MAOZ, 2009; SHLAIM, 2004; WEIZMAN, 2007). Assim, a desapropriação, discriminação e apartação em curso na Palestina/Israel está inter-relacionada com a ideologia colonial do pioneirismo ("conquista das fronteiras selvagens") e com motivações econômicas, demográficas, políticas e securitárias. Fica assim evidente que há um abuso retórico da suposta "necessidade de garantir a segurança israelense", servindo para justificar a 
judaização do território e a consequente segregação dos palestinos, há mais de meio século negando seus direitos fundamentais. O resultado é um território fragmentado, horizontal e verticalmente, com fronteiras em constante movimento, mas cuja lógica é a redução gradativa e concentração das áreas ocupadas pelo outro (WEIZMAN, 2007), estabelecendo-se uma "matriz de controle" que visa paralisar os movimentos do adversário (HALPER, 2000; 2009). As fronteiras coloniais ou "linhas abissais" teorizadas por Fanon (1963) e Santos e Meneses (2010) permanecem atuais.

Por fim, há que se destacar o movimento dos colonos, no pós-1967, como constituindo um sujeito coletivo autônomo, cujos interesses, de modo geral, convergem com o das autoridades israelenses, realizando os objetivos do sionismo como movimento nacional e colonial. Mas, também provoca tensões pela pressão que exerce no sentido de ter rédeas soltas para avançar na (des)apropriação do território, a despeito de tratados e da pressão internacional, que em alguns momentos levaram os governantes de Israel a ter que assumir compromissos de paralisar a expansão, nunca cumpridos de fato. Eis o maior mérito da obra de Akiva Eldar e Edith Zertal (2007): iluminar a relação dialética de colaboração e tensão dos colonos com as autoridades, desnudando os subterfúgios institucionais para garantir uma ajuda velada a sua expansão, tendo eles uma representatividade institucional crescente, integrando governos e ocupando cada vez mais posições, ao ponto de já conseguirem impedir manifestações contundentes de oposição a suas ações e à impunidade generalizada. São idealizados por muitos e muitas como os continuadores, os herdeiros diretos do "pioneirismo" dos primeiros sionistas, atualizando o imaginário orientalista.

\section{Colonização sionista e capitalismo}

Além dos elementos já trabalhados, é fundamental também submeter a realidade palestina, e médio-oriental como um todo, também às lentes da economia política, mais especificamente, a um olhar crítico, que revela outros componentes do sistema de ocupação/colonização, entendido agora a partir da exploração dos recursos naturais e humanos (sobretudo, terra, água e força de 
trabalho, esta ao menos até 1987). Historicamente, a empresa sionista, por meio de seus organismos, como a Organização Sionista Internacional, contou com importantes aportes de capital, sendo subvencionada por diferentes fontes. A colonização agrícola e o desenvolvimento urbano também foram pensados como meios de acumulação e expansão dos capitais envolvidos. Inclusive, a segregação também nessa seara é perceptível nos sindicatos, ainda do tempo do Mandato Britânico, que se pautavam pelo princípio da "libertação do trabalho", com o próprio Herzl já sugerindo não se empregar mão de obra nativa, o que se tornou uma constante.

Paralelamente, vigorava a lógica da "libertação da terra", com o MSI adquirindo o máximo possível de propriedades fundiárias, em detrimento do campesinato árabe-palestino, que passou a ter sua reprodução como classe negada dessa forma, ao serem expulsos após a reconfiguração das relações de propriedade o que, inclusive, está entre as primeiras causas do conflito interétnico, progressivamente agravado à medida que mais e mais terras eram perdidas, até a reversão drástica operada pela Guerra de Independência ou Nakba, que além de expulsar, desapropriou centenas de milhares de palestinos (FIELDHOUSE, 2006; GORNY, 1987; SUZMAN, 1999).

O jurista Henry Cattan (197-) definiu esse processo, operado em 1948, como um dos maiores roubos da história. A própria ONU, por meio de sua agência para os refugiados palestinos (UNRWA), começou a inventariar suas propriedades, que foram legalmente consideradas "abandonadas" por Israel e depois transferidas por uma série de leis arbitrárias, justificadas por questões nacionais e securitárias. Ou seja, ao passo que o retorno dos refugiados foi impedido à força, suas propriedades foram consideradas "vacantes" e passadas, inicialmente, a um órgão gestor e, posteriormente, diretamente a instituições e novos proprietários israelenses, sem custo algum. Eis uma vantagem competitiva para empreendimentos rurais, que inclusive passou a ser reproduzida nos TPO de 1967 em diante, ofertando produtos com menor custo produtivo, portanto, mais competitivos no mercado mundial.

Além da terra "gratuita", também é vantajosa a desobediência ao interdito de utilização da mão de obra palestina informal nas colônias, de custo muito 
inferior. Não raro, os antigos donos são empregados em suas propriedades desapropriadas, o que é uma constante na história do colonialismo ao redor do globo. Se até a Primeira Intifada havia uma exploração aberta e legalizada dessa força de trabalho, com sua superexploração gerando um considerável acúmulo de capital, após, com o fechamento e isolamento populacional cada vez maior, tal processo continua por meandros informais, em menor escala (SAID, 1988, 2006; WEIL, 2007).

Em uma perspectiva teórica mais ampla, podemos pensar a segregação e exploração a partir do conceito de “acumulação por espoliação”, cunhado por David Harvey $(2014,2016)$ sob inspiração de Marx e Rosa Luxemburgo, e de sua reflexão acerca dos meios ilícitos não serem elementos exógenos ao acúmulo de capital, mas fator constitutivo de sua lógica predatória. Desse modo, é possível compreender a lógica econômica mais ampla da expansão sionista sobre terras palestinas, desapropriadas e reaproriadas por uma lógica produtiva outra (obtenção de lucros no mercado internacional ao invés de reprodução do campesinato). Trata-se também de uma modernização capitalista conservadora e racista, que reproduz o mesmo itinerário dos colonialismos clássicos, etnicizando os espaços e os tornando produtivos na ótica do capital. Vale um paralelo com a teorização do sociólogo brasileiro José de Souza Martins (2018), que pensa as zonas de fronteira como de mortal conflitividade, limítrofes entre a lei e a alegalidade, entre a "civilização" e a "barbárie", onde coexistem diferentes relações de produção (sendo este o caso palestino até hoje, sobretudo, na Cisjordânia, onde não há uma regulamentação efetiva da obtenção da mais valia extraída do trabalho palestino ilegal e informal). Ou seja, formas "primitivas" de acúmulo do capital permanecem atuais.

Pensando, especificamente, no caso palestino, embasando-se nos teóricos da dependência, a economista estadunidense Sara Roy (1987) cunhou o conceito de "des-desenvolvimento". A economia palestina estaria atrelada à israelense, sendo dela dependente, o que impediria seu pleno desenvolvimento. À conquista e controle do território soma-se o domínio econômico, não só dos recursos (como terra, água e trabalho), mas de toda a estrutura produtiva, incluindo o fluxo e a natureza das mercadorias que podem ou não ser produzidas, criando reservas 
de mercado para produtores israelenses e garantindo a obtenção de produtos a um preço muito abaixo do mercado. Edward Said (1999, p. 20) já apontara que o desenvolvimento nos TPO seria impedido deliberadamente, permitindo-se, apenas, uma melhoria na situação econômica e social, desde que não resultasse em desenvolvimento autônomo. Conforme esse intelectual palestino, se o imperialismo é a teoria, o colonialismo é a prática de transformar territórios do ultramar em zonas produtivas e integradas ao sistema capitalista internacional, garantindo sua expansão e acúmulo, como por meio da superexploração da força de trabalho. Exemplo é a própria Palestina ocupada, onde (ao menos até 1987) os constantes deslocamentos drenaram boa parte dos salários, pois palestinos já não podiam residir dentro de Israel, sendo uma força de trabalho migratória e empobrecida em seu próprio país (SAID, 1988, 1992, 1999).

Pensando no neocolonialismo (N'KRUMAH, 1967), em nosso caso específico, ao invés de suceder o colonialismo é, contraditoriamente, sincrônico. Essa estrutura espoliativa é constituída pela desapropriação e segregação gradativas, assim como pela discriminação, informalidade, ilegalidade e superexploração. As decorrentes desigualdades de renda e acesso a meios produtivos e serviços básicos, seja em Israel seja nos "Territórios Ocupados", estão explícitas em qualquer censo ou pesquisa séria (ADALAH, 2011; ARAB ASSOCIATION FOR HUMAN RIGHTS, 2006; HUMAN RIGHTS WATCH, 2010; MOSSAWA CENTER, 2009). Conforme o geógrafo israelense Oren Yiftachel (2006), além dos fluxos étnicos de capital serem constituintes do sionismo e da etnocracia israelense, a judaização dos territórios ocupados e colonizados a partir de 1967 reflete, em grande medida, o que ocorrera antes com a população palestina que conseguiu permanecer em suas terras dentro de Israel, sendo estas grosseiramente reduzidas, boa parte expropriada, limitada espacialmente e, gradativamente, cercada por assentamentos israelenses. A territorialização é um processo étnico, mas também econômico, que foi e ainda é bifronte, sendo o caso mais explícito os TPO e, dentro das fronteiras de Israel, os beduínos no sul do país, reduzidos a reservas diminutas. No entanto, há subdivisões significativas dentro dos grupos étnicos, que levam Yiftachel a recorrer ao conceito de etnoclasse, sendo os judeus de origem europeia hegemônicos. 
Considerando-se isso tudo da perspectiva pós-colonial, não é novidade a sobreposição entre raça e classe no processo de expansão e acúmulo do capital, ou como este se valeu da racialização das relações produtivas para potencializar a extração de mais-valia (QUIJANO, 2010), reproduzindo-se condições semelhantes ao acúmulo primitivo até hoje na Palestina e demais zonas de fronteira, ou "lado de lá" das linha abissais que separam a civilização e a lei da barbárie e "alegalidade", onde tudo pode e é promovido em termos de exploração ou mesmo genocídio e limpeza étnica (SANTOS, 2010).

\section{Os dois paradigmas da ocupação israelense}

Pensando exclusivamente a ocupação dos territórios palestinos a partir de 1967, o historiador israelense, Neve Gordon (2008), traz uma contribuição significativa à compreensão das políticas e práticas de segregação e discriminação. Estão implícitas em sua abordagem muitas das causalidades acima apontadas e ele não ignora que uma resolução definitiva do conflito deva considerá-lo na íntegra, para muito além de uma simples questão de "ocupação", afinal os enfrentamentos contemporâneos entre guerrilhas palestinas e o Estado israelense são, em partes, continuidade da colonização inicial, que culminou na limpeza étnica durante e depois da guerra de 1948 (é o próprio autor que recorre à expressão notabilizada por Ilan Pappe). Há contradições latentes, como o problema dos refugiados palestinos, a fragmentação intencional dos territórios, a relação complexa e contraditória com a Cisjordânia (separada, mas integrada, em grande parte colonizada, mas não anexada) e o gradativo aumento da população de colonos israelenses.

Gordon sugere que essa complexidade, essa ambiguidade jurídica, ajuda a ocultar as práticas segregacionistas e discriminatórias, mantendo os mitos nacionais, como Israel ser "a única democracia do Oriente Médio", embora, desde 1967, boa parte dos habitantes de todos os territórios controlados por Israel não seja considerada cidadã e esteja privada de direitos básicos. É convergente com a "fachada democrática" como uma das características das etnocracias, com o papel da Alta Corte de Justiça de Israel em legitimar as ações do governo, não obstante decisões pontuais em contrário (KRETZMER, 2002), com a utilização da 
lei nos TPO como ferramenta de controle e consolidação da ocupação/colonização (SHEHADEH; KUTTAB, 1980) e com o que Eyal Weizman (2007) define como "política do caos", com as vidas e propriedades palestinas vulnerabilizadas pela não aplicação ou por interpretações ambíguas das leis, por dispositivos de emergência ou exceção legal normalizados e por outros subterfúgios.

A maior contribuição de Gordon (2008, p. 1-20) está na historicização da ocupação, periodizando-a a partir de cinco recortes (governo militar, 1967-1980; administração civil, 1981-1987; Primeira Intifada, 1988-1993; Anos de Oslo, 19942000; Segunda Intifada, 2001-2006)) e de dois "paradigmas", mostrando continuidades e rupturas ao longo de quatro décadas. A Primeira Intifada seria o ponto de clivagem, quando, diante de sua falência, Israel passou a operar a substituição do paradigma até então dominante, fundado no "princípio da colonização”. Gradativamente, abandonou a tentativa de normalizar e invisibilizar a ocupação, que administrava, mas não integrava de fato a população palestina, enquanto garantia a exploração de seus recursos, como terra, água e trabalho. 0 novo paradigma foi sendo gestado, até se consolidar da Segunda Intifada em diante, alicerçando-se no "princípio da separação" que, ao contrário do modelo anterior, enfatiza mais o poder soberano (aplicar ou suspender a lei, provocando mais mortes) do que o disciplinar e o biopoder, abandonando parte dos esforços de administração da vida dos colonizados, mas mantendo a exploração da água e terra.

Ou seja, diante da recusa palestina à normalização da ocupação, que culminou em um massivo levante anticolonial, o Estado israelense alterou seus métodos, substituindo a "política de vida" (mais próxima do modelo clássico de apartheid) por uma "de morte". Valendo-se das considerações foucaultianas, Gordon (2008) pensa no controle exercido sobre as vidas, propriedades e corpos palestinos a partir de três modos de poder (disciplinar, soberano e biopoder), com a ênfase em cada um ao longo do tempo alterando as formas de controle e definindo um modelo, um (sub)período. Nem tanto substituição de um pelo outro, ou modificação radical nos meios de poder ou controle, mas mudança de ênfase, haja vista a sincronia de mecanismos, instituições, práticas e dispositivos 
coercitivos, legais e burocráticos, operando tanto nos indivíduos quanto nas populações para "produzir novas formas de comportamento, hábitos, interesses, gostos e aspirações".

De forma geral, essas modificações concretas na forma de controle dos TPO se devem à interação múltipla e complexa de fatores, mais a elementos estruturais contraditórios do que a decisões particulares, sendo os mecanismos monitorados e revisados constantemente, conforme os efeitos gerados. Tal ótica é consonante e complementar às reflexões político-espaciais de Weizman (2007) e Halper (2000; 2009), e partilha do referencial foucaultiano, igualmente caro à Zureik (2016).

No coração dessa engenharia social complexa e cambiante está a separação entre território desejado e população rejeitada, ou a velha "questão oculta", com as instituições israelenses já preparando a administração dos TPO mesmo antes de 1967, de modo a garantir a posse, ocupação e colonização (variando a motivação ideológica conforme cada grupo), mas sem integrar os palestinos como cidadãos. Se em 1948 foi possível uma limpeza étnica em grande escala, 1967 (que "transferiu" ou "limpou” outras centenas de milhares de palestinos) atualizou o problema "dois povos, uma terra" e reacendeu os debates sobre as fronteiras e as expectativas messiânicas, havendo desde o final da Nakba uma convergência entre diferentes setores do espectro ideológico sionista quanto à necessidade de ampliar o território resultante da "Guerra de Independência", sendo o problema, novamente, o que fazer com seus habitantes palestinos. Tais considerações são comuns na bibliografia (MASALHA, 2000; SHLAIM, 2004; YIFTACHEL, 2006; GORDON, 2008). Cada região capturada em 1967 foi tratada de forma distinta: Jerusalém e Golã anexadas, assim como se ambiciona para a Cisjordânia, gradativamente colonizada, distintamente de Gaza, onde essa lógica foi abandonada e o território cercado e isolado, de 2005 em diante, constituindo-se em um possível modelo final de gestão dos palestinos concentrados em um mínimo possível de território (LI, 2006), e reduzidos à condição de homo sacer (ZUREIK, 2016; SAHD, 2017).

Em suma, diante dos interesses hegemônicos em cada área e da clara distinção entre território ocupado e população, as políticas e práticas de controle 
sobre a vida e propriedades dos palestinos são variáveis, mas não a discriminação, desapropriação e segregação típicas dos colonialismos. Estas são efetivadas por meio de medidas gradativas ou drásticas, como transferência populacional (limpeza étnica abrupta ou pontual, com medidas que inviabilizam a permanência em determinados locais, como Jerusalém e o Vale do Jordão, gradativamente, despalestinizados), anexação territorial, colonização informal e massacres punitivos exemplares, como os operados em Gaza no novo milênio (SAHD, 2017). Israel adota formas de controle discriminatórias e segregacionistas (e por isso denunciadas na relatoria da ONU e de ONGs), assim como uma série de mecanismos de expropriação para judaizar o território, sem incorporar seus habitantes, mantidos em um limbo legal (nem cidadãos nem população oficialmente vivendo sob ocupação), portanto, vulnerabilizados intencionalmente (GORDON, 2008).

\section{A etnocracia israelense: uma síntese conceitual possível}

O conceito de etnocracia foi formulado pelo geógrafo israelense Oren Yiftachel e apresentado em seu formato final em 2006 para definir a configuração do Estado ocupante e constitui uma relevante chave teórica, moldada a partir de uma conjugação das três "forças históricas" apresentadas até aqui. Expor com mais detalhes a constituição dessa etnocracia, em especial, e como ela sintetiza as forças do colonialismo, nacionalismo e capitalismo (espacial e temporalmente interseccionadas) é um modo de concluir o presente balanço bibliográfico. Inclusive, o próprio Yiftachel menciona como o caso específico analisado serve para ilustrar muitas características gerais dessas "forças", a exemplo da inerente possibilidade de os "nacionalismos modernos" operarem limpezas étnicas em situações de geografia mista, motivados pelo mito do Estado-nação puro, o que também é percebido por outros autores (APPADURAI, 2009).

Israel é definido como uma etnocracia cuja razão de ser é promover o processo de "judaização" da Palestina, que por sua vez constitui o eixo articulador do conflito. Não se configura como democracia por não ter fronteiras definidas nem a soberania estar nas mãos de todo seu demos, mas sim de uma das etnias em disputa, que tem direito à cidadania independentemente do território que 
ocupa (Israel, os TPO ou o estrangeiro). O país se consolidou como etnocracia quando uma das etnias em disputa (subdividida em uma etnoclasse dominante e outra secundária) conseguiu se apropriar do Estado, em 1948, e aparelhá-lo para avançar em seus interesses étnicos coletivos, sobretudo, a expansão territorial, em detrimento da alteridade.

Inclusive, a premissa da "transferência" populacional como meio de resolução da "questão oculta" não só viabilizou a formação do Estado judeu, como segue presente no debate público como alternativa para uma solução final. É a lógica da reivindicação de soberania exclusiva sobre um território em disputa que implica a negação dos direitos do outro, cuja presença é vista como obstáculo à realização do projeto etnonacional, de modo que políticas discriminatórias e de apartação estão na própria base institucional. Decorre da colonização e judaização do território o que Yiftachel define como "apartheid gradativo", que nega a autodeterminação palestina, limita sua presença espacial e suprime suas formas de resistência.

Desse modo, desde 1948, a etnoclasse hegemônica aparelha as instituições para manter e expandir seu poder, valendo-se do controle discricionário das políticas demográficas, forças armadas, políticas fundiárias e de planejamento, do sistema legal, fluxos de capital e cultura pública. São as bases do regime que promovem a etnicização territorial (logo, a discriminação e segregação da alteridade), mas que enfrentam "contraforças" ou fatores de democratização, que provocam sua desestabilização, como a resistência de minorias (sejam judaicas progressistas, sejam palestinas), a globalização e a atuação de organizações civis por direitos, informadas pelos regimes morais internacionais (como o Direito Internacional dos Direitos Humanos), com os quais a lógica discriminatória da etnocracia se choca frontalmente (reflexo disso são a relatoria e as resoluções condenatórias da ONU). Para Yiftachel (2006, p. 36-37; p. 44-47), a espinha dorsal do conflito é esse projeto de "judaização" da Palestina/Israel e a resistência a ele, com esse processo assumindo diferentes contornos, conforme mudam e se reconstituem as correlações de força, o que foi percebido e estrutura a periodização proposta por Neve Gordon (2008), com base nas continuidades e rupturas da ocupação. Invariavelmente, permanece a fratura 
entre quem tem cidadania israelense e direitos e quem está destituído até de uma condição jurídica segura, estando os palestinos dos TPO sujeitados à justiça militar - cujos julgamentos são, geralmente, tendenciosos, sumários (HAJJAR, 2005) -, a uma permanente restrição de moradia e movimento e à exploração e esbulho de suas terras, sendo violentados impunemente e considerados parte de uma população que vive "sob ocupação", embora sequer Israel reconheça esta como tal perante o direito humanitário internacional, só aplicando parcialmente as Convenções de Genebra.

Enquanto isso, os colonos têm cidadania, respondem na justiça civil e desfrutam de vários benefícios, como acesso à água, estradas exclusivas, planos diretores, políticas habitacionais e linhas de crédito. Mas, diferentemente da explícita e positivada apartação promovida outrora na África do Sul, é central para a perpetuação da segregação operada pela etnocracia israelense, a dissimulação das violações de direitos que são inerentes a seu regime e práticas decorrentes, que é o que Yiftachel chama de manutenção de uma fachada democrática. Vale destacar que a discriminação não ocorre somente nos TPO, mas também dentro do território israelense, conforme as fronteiras de 1949, como apontam distintos autores e relatórios de direitos humanos (ADALAH, 1998; MOSSAWA, 2009; PAPPÉ, 2015). Conforme Shany Payes (2005), o status civil e a posição socioeconômica da minoria palestina com cidadania israelense ("árabes israelenses") são afetados pela contraditória definição de Israel como, simultaneamente, uma democracia e um Estado judeu.

Os judeus dominam a economia israelense, com os palestinos ocupando os cargos remunerados mais baixos. Os últimos vivem sobretudo em municipalidades ou vizinhanças separadas em cidades mistas e estudam em escolas separadas, mas as cidades e vilas árabes estão localizadas na periferia israelense e ambas, as escolas e as municipalidades, são dependentes, para sua manutenção, de um sistema de alocação de recursos discriminatório e controlado por judeus. O currículo das escolas árabes é desenvolvido e está alinhado com os mesmos valores e objetivos sionistas que caracterizam o currículo escolar israelense em geral. Israel é uma sociedade altamente segregada, com tanto a minoria quanto a maioria preferindo manter residência separada e casar dentro da comunidade (PAYES, 2005, p. 6-7).

A natureza limitada e desigual dos encontros entre judeus e palestinos em Israel é refletida na organização institucional das duas comunidades (PAYES, 2005, p. 191). 


\section{Conclusão}

Em suma, na compreensão da segregação e discriminação na Palestina, temos acordo com Yiftachel (2006) quanto ao entrecruzamento entre nacionalismo, colonialismo e capitalismo no processo de "judaização" do território, que se constitui no elemento central para a compreensão das políticas de discriminação e segregação mantidas há décadas pelo Estado israelense. Sustentam essa abordagem multidimensional, espécie de guarda-chuva que contempla as demais, as informações compiladas por diferentes ONGs e órgãos da ONU, como a relatoria especial ligada ao Conselho de Direitos Humanos (a exemplo do relatório de Falk, a partir do qual introduzimos o presente artigo) e a série documental produzida pelo "Comitê Especial para Investigar as Práticas Israelenses Afetando os Direitos Humanos da População dos Territórios Ocupados" (CEIPI), criado pela Comissão de Direitos Humanos da ONU, que aborda, desde o final dos anos 1960, mortes, torturas, desapropriações, leis de controle e apartação, fundação de colônias, assim como discursos racistas e nacionalistas de autoridades e lideranças israelenses.

Desse modo, a definição de Israel como etnocracia, além de sintetizar parte do debate bibliográfico, é útil para pensar as considerações presentes desde os primeiros relatórios de direitos humanos e humanitários. As violações, e mais especificamente as políticas discriminatórias e segregacionistas, são reflexos das medidas adotadas para "judaizar" o território, controlar, "transferir" e concentrar os palestinos em áreas mínimas enquanto sua resistência é suprimida. Também refletem esse objetivo territorial central da etnocracia tanto a sistemática ineficácia das "recomendações" feitas há décadas em documentos de ONGs e da ONU para Israel ajustar suas condutas, quanto a impunidade generalizada de colonos, militares, políticos e funcionários israelenses, que violam os direitos mais elementares da população palestina.

Tal lógica foi apenas sintetizada por Yiftachel, sendo denunciada há tempos por diversos autores e relatórios de direitos humanos, a exemplo da resolução 2851 (XXVI) da Assembleia Geral, datada de dezembro de 1971, por meio da qual a ONU incorporou a denúncia feita pelo CEIPI, instando com veemência 
Israel a desistir da "[...] evacuação, transferência, deportação e expulsão dos habitantes dos territórios árabes ocupados" e da "[...] destruição e demolição de aldeias, quarteirões e casas, e do confisco e expropriação de propriedades" (UNITED NATIONS, 1971). Como já visto, mais de quatro décadas depois, o relatório de Falk (2014) apontou conclusão semelhante, mas em um contexto de vigência de outro paradigma da ocupação, caracterizado por maior segregação e violência e pela continuidade dos deslocamentos forçados e do desejo de uma solução final, como uma grande transferência ou expulsão dos palestinos de Israel e dos TPO (PAPPE, 2008).

Enquanto isso, os governantes do país vêm se esforçando para manter a "fachada democrática”, dissimulando as violações estruturais, parte da própria constituição do país como um Estado étnico segregacionista, mas que tem que conviver e manter sua legitimidade perante os "regimes morais internacionais" e suas instituições, como a ONU. Em suma, por detrás da fachada democrática, a realidade da duradoura apartação na Palestina está sistematicamente registrada pela bibliografia e fundamentada em testemunhos, periódicos e na relatoria da ONU e de diferentes ONGs. Já o conceito de etnocracia, embora apresente suas falhas, assim como toda tentativa de generalização, apresenta-se como um guia muito útil para nos conduzir por essa situação de generalizado desrespeito aos direitos humanos.

\section{Referências}

ABUNIMAH, Ali. One country: a bold proposal to end the Israeli-Palestinian impasse. New York: Metropolitan books; Henry Holt and Company, 2006.

ADALAH. Legal violations of Arab minorities in Israel: a report on Israel's implementation of the International Convention on the Elimination of all Forms of Racial Discrimination. Adalah web site, [S.l..], Mar. 1998. Available in: http://www.adalah.org/eng/publications/violations.htm. Access in: 13 June 2011. 
ALAM, Shahid. Israeli exceptionalism: the destabilizing logic of Zionism. New York: Palgrave Macmillan, 2009.

ANDERSON, Benedict. Comunidades imaginadas: reflexões sobre a origem e difusão do nacionalismo. São Paulo: Companhia das Letras, 2008.

APPADURAI, Arjun. O medo ao pequeno número: ensaio sobre a geografia da raiva. São Paulo: Iluminuras, 2009.

ARAB ASSOCIATION FOR HUMAN RIGHTS. On the margins: annual review of human rights violations of the Arab Palestinian minority in Israel, 2006.

Nazareth, 2006. Available in:

http://www.arabhra.org/HraAdmin/UserImages/Files/YearlyReport2006FullVersio nHighQualityEnglish.pdf. Access in: 13 Mar. 2020.

AMNESTY INTERNATIONAL. Israel and the occupied territories: road to nowhere. London: Amnesty International Publications, 2006. Available in: https://www.amnesty.ie/wp-content/uploads/2016/05/Israel-and-theOccupied-Territories.-The-road-to-Nowhere.pdf. Access in: 22 Apr. 2020.

AMNESTY INTERNATIONAL. Enduring occupation: palestinians under siege in the west bank. London: Amnesty International, 2007. Available in : https://www.amnesty.ie/wp-content/uploads/2016/05/Report-EnduringOccupation.pdf. Access in: 22 Apr. 2020.

BIMKOM. From public to national: national parks in East Jerusalem. Jerusalem: Bimkon, 2012. Available in: http://bimkom.org/eng/wpcontent/uploads/FromPublic-toNational_English_FINAL2012_withMAPS_lowres1.pdf. Access in: 13 June 2015.

BIMKOM; B'TSELEM. The hidden agenda: the establishment and expansion plans of Ma'ale Adummim and their human rights ramifications. Jerusalem: Bimkom, 2009. Available in:

http://www.btselem.org/download/200912_maale_adummim_eng.pdf. Access in: 20 Nov. 2014.

BISHARA, Marwan. Palestina/Israel: a paz ou o apartheid. São Paulo: Paz e Terra, 2003.

BOBBIO, Norberto. Direita e esquerda: razões e significados de uma distinção política. 3. ed. São Paulo: Editora Unesp, 2011.

BOUSSOIS, Sébastien. Israël confronté a son passé. Paris: L'Harmattan, 2008. 
CATTAN, Henry. A Palestina e o direito internacional: o aspecto legal do conflito Árabe-Israelense. Curitiba: Grafipar, [197-].

CIVIC COALITION FOR DEFENDING PALESTINIANS RIGHTS IN JERUSALEM. Aggressive urbanism: urban planning and the displacement of palestinians within and from occupied east Jerusalem. Jerusalem, 2009. Available in: http://civiccoalitionjerusalem.org/system/files/documents/aggressive_urbanism. pdf. Access in: 13 June 2015.

CoconI, Luciana. Apartheid contra el pueblo palestino. Madrid: Ediciones del Oriente y del Mediterráneo, 2010.

CORNEVIN, Marianne. Apartheid, poder e falsificação histórica. Lisboa: Edições 70, 1982.

D’AMOURS, Jillian K. New Israeli laws threaten Palestinian civil society. Chicago: The eletronic intifada, [S.l.], 06 Dic. 2010. Available in: http://electronicintifada.net/content/new-israeli-laws-threaten-palestinian-civilsociety/9123\#.TttzmFbPyql. Access in: 14 Nov. 2015.

D'AMOURS, Jillian K. Israel criminalizes commemoration of the Nakba. The Eletronic Intifada, Chicago, 29 mar. 2011. Available in: http://zochrot.org/en/content/israel-criminalizes-commemoration-nakba. Access in: 14 Nov. 2015.

ENRIQUEZ, Eugène. Matar sem remorso: reflexões sobre os assassinatos coletivos. História - questões \& debates: os lugares da violência, Curitiba: Editora da UFPR, v. 18, n. 35, p. 11-41, jul./dez. 2001.

EPSTEIN, Yitzhak. The hidden question. [S.l.], Aug. 1907. Available in: http://qumsiyeh.org/yitzhakepstein/. Access in: 31 Oct. 2014.

FALK, Richard. Achieving human rights. New York: Routledge, 2009.

FANON, Frantz. Los condenados de la tierra. Cidade do México: Fondo de Cultura Económica, 1963.

FIELDHOUSE, David K. Western Imperialism in the Middle East: 1914-1958. Oxford: Oxford University Press, 2006.

GORDON, Neve. Israel's occupation. Los Angeles: University of California Press, Ltd., 2008. 
GORNY, Yosef. Zionism and the arabs, 1882-1948: a study of ideology. Oxford: Clarendon Press, 1987

GRESH, Alain. A persistência da visão colonial: Israel-Palestina, um plano de guerra. Le Monde Diplomatique Brasil, Santa de Parnaíba, p. 26-27, 2020.

HAJJAR, Lisa. Courting conflict: the Israeli military court system in the West Bank and Gaza. Berkeley: University of California Press, 2005.

HALPER, Jeff. The 94 percent solution: a matrix of control. Middle East Research and Information Project, [Chicaco], 2000. Available in: http://www.merip.org/mer/mer216/94-percent-solution. Access in: 15June 2015.

HALPER, Jeff. Dismantling the matrix of control. Middle East Research and Information Project, [Chicaco], 2009. Available in:

http://www.merip.org/mero/mero091109. Access in: 1 June 2015.

HARVEY, David. O novo imperialismo. 8. ed. São Paulo: Edições Loyola, 2014.

HARVEY, David. Dezessete contradições e o fim do capitalismo. São Paulo: Boitempo, 2016.

HERZL, Theodor. O Estado judeu. São Paulo: Organização sionista unificada do Brasil, 1947.

HUMAN RIGHTS WATCH. Separate and unequal: Israel's discriminatory Treatment of palestinians in the occupied Palestinian Territories. New York: Human Rights Watch, 2010. Available in:

http://www.hrw.org/sites/default/files/reports/iopt1210webwcover_0.pdf. Access in: 13 June 2014.

KRETZMER, David. The Occupation of justice: the Supreme Court of Israel and the occupied territories. Albany: SUNY Press, 2002.

LAOR, Yitzhak. Las falacias del sionismo progressista. Barcelona: Edicions Bellaterra, 2012.

LI, Darryl. The Gaza strips as laboratory: notes in the wake of disengagement. Journal of Palestine Studies, Beirute, v. 35, n. 2, p. 38-55, 2006.

MOSSAWA CENTER. Main findings of the 2009-2010 state budget proposal and the needs of the Arab citizens in Israel. Mossawa Center web site. [S.l.], July de 2009. Available in:

http://mossawa.org/files/files/File/Publications/Main\%20findings\%20of\%20the\% 202009- 
2010\%20State\%20Budget\%20Proposal\%20and\%20the\%20needs\%20of\%20Arab \%20Citizens\%5B1\%5D.pdf. Access in: 18 Mar. 2011.

MAOZ, Zeev. Defending the Holy Land: a critical analysis of Israel's security and foreign policy. Ann Arbor: University of Michigan Press, 2009.

MARTINS, José de Souza. Fronteira: a degradação do outro nos confins do humano. São Paulo: Editora Contexto, 2018.

MASALHA, Nur. Imperial Israel and the palestinians: the politics of expansion. London: Pluto Press, 2000.

MASALHA, Nur. Expulsión de los palestinos: el concepto de "transferencia" en el pensamiento político sionista, 1882-1948. Buenos Aires: Editorial Canaán, 2008.

N'KRUMAH, Kwame. Neocolonialismo: último estágio do imperialismo. Rio de Janeiro: Editora Civilização Brasileira, 1967.

OSMAN, Firoz; DADOO, Suraya. Why Israel?: the anatomy of Zionist apartheid: a South Africa perspective. Johannesburg: Media Review Network; Porcupine Press, 2013.

PAPPE, Ilan. The ethnic cleansing of Palestine. Oxford: Oneworld Publications, 2008.

PAPPE, Ilan (ed.). Israel and South Africa: the many faces of Apartheid. London: Zed Books, 2015.

PAYES, Shany. Palestinian NGOs in Israel: the politics of civil society. New York: St. Martin's Press, 2005.

PINSKY, Jaime. Origens do nacionalismo judaico. São Paulo: Editora Hucitec, 1978.

QUIJANO, Aníbal. Colonialidade do poder e classificação social. In: SANTOS, Boaventura de Sousa; MENESES, Maria Paula (org.). Epistemologias do sul. São Paulo: Cortez, 2010. p. 73-118.

RABKIN, Yakov. M. Judeus contra judeus: a história da oposição judaica ao sionismo. Cotia: Acatu, 2009.

ROY, Sara. The Gaza strip: a case of economic de-development. Journal of Palestine Studies, Beirute, v. 17, n. 1, p. 56-58, 1987. Available in:

http://www.palestine-studies.org/files/pdf/jps/1069.pdf. Access in: 28 dez. 2011. 
SAHD, Fabio B. Oriente Médio desmistificado: terrorismo, fundamentalismo e barbárie. Curitiba: Editora CRV, 2010.

SAHD, Fabio B. As violações impunes de direitos humanos e humanitários dos palestinos vivendo sob a ocupação israelense: possíveis interpretações. 2017. Tese Doutorado em Ciências) - Universidade de São Paulo, São Paulo, 2017. Disponível em: https://teses.usp.br/teses/disponiveis/8/8161/tde-21022018102435/publico/2017_FabioBacilaSahd_VOrig.pdf. Acesso em: 22 abr. 2020.

SAID, Edward W. et al. A profile of the Palestinian people. In: SAID, Edward W.; HITCHENS, Christopher (ed.). Blaming the victims: spurious scholarship and the Palestine Question. London: Verso, 1988. p. 235-296.

SAID, Edward W. Orientalismo: o Oriente como invenção do Ocidente. São Paulo: Companhia das Letras, 2007.

SAID, Edward W. The question of Palestine. New York: Vintage Books, 1992.

SAID, Edward W. How do you spell Apartheid?: O-S-L-O. Ha'aretz, Jerusalem, 11 Oct. 1998.

SAID, Edward W. After the last sky. New York: Columbia University Press, 1999.

SAID, Edward W. Cultura e resistência: entrevistas do intelectual palestino a David Barsamian. Rio de Janeiro: Ediouro, 2006.

SAND, Shlomo. Comment le peuple juif fut inventé. Paris: Fayard, 2008.

SANTOS, Boaventura de Sousa. Para além do pensamento abissal: das linhas globais a uma ecologia de saberes. In: SANTOS, Boaventura de Sousa;

MENESES, Maria Paula (orgs.). Epistemologias do Sul. São Paulo: Cortez, 2010. p. 23-72.

SANTOS, Boaventura de Sousa; MENESES, Maria Paula (org.). Epistemologias do sul. São Paulo: Cortez, 2010.

SHLAIM, Avi. A muralha de ferro: Israel e o mundo árabe. Rio de Janeiro: Fissus, 2004.

SHEHADEH, Raja; KUTTAB, Jonathan (ed.). The West Bank and the rule of the law. Genebra: The International Commission of Jurists: Law in the Service of Man: 1980.

SHELEF, Nadav G. Evolving nationalism: homeland, identity and religion in Israel, 1925-2005. Ithaca: Cornell University Press, 2010. 
SUZMAN, Mark. Ethnic nationalism and state power: the rise of Irish nationalism, Afrikaner nationalism and zionism. New York: St. Martin's press inc., 1999.

UNITED NATIONS. General assembly: resolution 2851 (XXVI): report of the special committee to investigate israeli practices affecting the human rights of the population of the occupied territories. [S.l.]: UN, 20 Dic. 1971. Available in: https://unispal.un.org/DPA/DPR/unispal.nsf/O/DC39D8D9B0DADCF6852560DE00 6B70B5. Access in: 22 Apr. 2020.

UNITED NATIONS. Human rights council: implementation of general assembly resolution 60/251 of 15 march 2006 entitled "human rights council": report of the special rapporteur on the situation of human rights in the palestinian territories occupied since 1967, John Dugard. [S.L.]: UN, 29 Jan. 2007. Available in: https://documents-dds-

ny.un.org/doc/UNDOC/GEN/G07/105/44/PDF/G0710544.pdf?OpenElement. Access in: 22 Apr. 2020.

UNITED NATIONS. Human rights council: human rights situation in palestine and other occupied arab territories: report of the special rapporteur on the situation of human rights in the palestinian territories occupied since 1967, John Dugard. [S.L.]: UN, 21 Jan. 2008. Available in: https://documents-ddsny.un.org/doc/UNDOC/GEN/G08/402/29/PDF/G0840229.pdf?OpenElement. Access in: 22 Apr. 2020.

UNITED NATIONS. Human rights council: human rights situation in palestine and other occupied arab territories: report of the special rapporteur on the situation of human rights in the palestinian territories occupied since 1967, Richard Falk. [S.l.]: UN, 13 Jan. 2014. Available in: http://blog.unwatch.org/wpcontent/uploads/A-HRC-25-67_en-Falkfinalreport_Feb2014.pdf. Access in: 19 Jan. 2014.

UNITED NATIONS. Economic and social commission for Western Asia: Israeli practices towards the palestinian people and the question of Apartheid. Beirute: United Nations, 2017. Available in: https://www.middleeastmonitor.com/wpcontent/uploads/downloads/201703_UN_ESCWA-israeli-practices-palestinianpeople-apartheid-occupation-english.pdf. Access in: 27 Mar. 2017.

WEIL, Josef (org.). O Oriente Médio na perspectiva marxista. São Paulo: Editora Sundermann, 2007.

WEIZMAN, Eyal. Hollow Land: Israel's architecture of occupation. London: Verso, 2007.

YIFTACHEL, Oren. Ethnocracy: land and identity politics in Israel/Palestine. Philadelphia: University of Pennsylvania Press, 2006. 
ZERTAL, Idith; ELDAR, Akiva. Lords of the land: the war over Israel's settlements in the occupied territories, 1967-2007. New York: Nation Books, 2007.

ZERTAL, Idith. La nación y la muerte. la Shoá en el discurso y la política de Israel. Buenos Aires: Del Nuevo Extremo, 2010.

ZUREIK, Elia. Israel's colonial project in Palestine. Brutal Pursuit. London: Routledge, 2016. 